\title{
Updated Framework on The Dissemination of Capacity Development Information
}




\section{UPDATED FRAMEWORK ON THE DISSEMINATION OF CAPACITY DEVELOPMENT INFORMATION}

IMF staff regularly produces papers proposing new IMF policies, exploring options for reform, or reviewing existing IMF policies and operations. The following document(s) have been released and are included in this package:

- The Staff Report prepared by IMF staff and completed on January 7, 2022.

The report prepared by IMF staff has benefited from comments and suggestions by Executive Directors following the informal session on January 26, 2022. Such informal sessions are used to brief Executive Directors on policy issues and to receive feedback from them in preparation for a formal consideration at a future date. No decisions are taken at these informal sessions. The views expressed in this paper are those of the IMF staff and do not necessarily represent the views of the IMF's Executive Board.

The IMF's transparency policy allows for the deletion of market-sensitive information and premature disclosure of the authorities' policy intentions in published staff reports and other documents.

Electronic copies of IMF Policy Papers are available to the public from http://www.imf.org/external/pp/ppindex.aspx

\section{International Monetary Fund Washington, D.C.}




\section{INTERNATIONAL MONETARY FUND}

\section{UPDATED FRAMEWORK ON THE DISSEMINATION OF}

CAPACITY DEVELOPMENT INFORMATION

\section{EXECUTIVE SUMMARY}

The IMF's capacity development (CD) information dissemination policy needs to adapt to a new landscape. The Fund is providing more $C D$ and producing greater and more diverse types of CD-related information. Meanwhile, the external landscape has also evolved, as members, partners, and other CD providers increasingly expect greater transparency and access to information.

\section{The 2018 CD Strategy Review advocated for wider dissemination of CD} information, while protecting staff candor and the role as trusted advisor.

Dissemination yields many benefits, including fostering stronger ownership, improving coordination internally as well as with other CD providers and financing partners, promoting accountability, and advancing the Fund's contribution to knowledge as a global public good. The 2018 Review concluded that, while there had been progress in the dissemination of $C D$ information to a wider range of stakeholders, publication rates of technical assistance (TA) reports remained low, and the dissemination policy had gaps in coverage.

This framework paper sets forth updates to the policy. The outlines of the TA dissemination policy were originally set out in a background paper on Dissemination of Technical Assistance Information ("2008 Framework Paper") that informed a Board discussion on enhancing the impact of Fund technical assistance. The policy was then formalized in the 2009 Staff Operational Guidelines on Dissemination of Technical Assistance Information ("Operational Guidelines"), which were updated in 2013 and 2020. This paper sets out envisaged reforms to further widen the dissemination and publication of CD information. The specific reforms include:

- Broadening the CD dissemination policy's scope, including by creating a category of "final CD output," which expands coverage to all CD information, including TA advice, training, and other forms of CD output.

- Moving towards the default publication of high-level summaries of strategic final CD outputs on a lapse-of-time basis with streamlined internal processes for producing such summaries.

- Simplifying the publication process for final CD outputs by eliminating posttransmittal corrections and deletions. 
- Improving $C D$ surveillance integration by enabling $C D$ department staff to further share $C D$ information relevant to program work or surveillance with staff in other departments.

- Reducing delays in the dissemination of final CD outputs to direct financing partners and Executive Directors by introducing Fund-wide norms and shortening the timeline for lapse-oftime consent.

- Clarifying the policy on the dissemination of Fund assessment (including evaluation) information to improve consistency in its application.

- Clarifying the policy on the dissemination of CDMAP information beyond Fund staff, including to direct financing partners and Executive Directors. 
Approved By

Roger Nord and

Rhoda Weeks-Brown
Prepared by the Institute for Capacity Development (ICD) and Legal Department in consultation with other departments, under the guidance of Michaela Erbenova (ICD) and Bernhard Steinki (LEG).

\section{CONTENTS}

A. Some Types of CD Output are Not Covered by the Current Policy _ $\underline{7}$

B. Publication Rates of Final TA Reports Remain Very Low___ $\underline{8}$

C. Revisiting the Corrections and Deletions Rules__ $\underline{9}$

D. Delays and Gaps in Dissemination of Final TA Reports __ 10

E. Lack of Clarity Over Other Types of CD Information__ 12

PLANNED POLICY REFORMS _ 13

A. Expanding the Scope of the Policy___ 14

B. Raising Publication Rates of Final CD Output __ 14

C. Limiting Post-Transmittal Modifications___ 16

D. Increasing the Timeliness and Coverage of Dissemination of CD Information__ 16

E. Clarifying Policy for Existing CD Information Types___ 18

IMPLEMENTATION___ $\underline{\mathbf{2 1}}$

BOX

1. Treatment of CD Information Under Fund Policies

\section{FIGURES}

1. Capacity Development Spending___ $\underline{4}$

2. IMF Training Participants__ $\underline{8}$

3. Field and Virtual CD Missions__ $\underline{8}$

4. Publication Statistics__ $\underline{8}$

5. TA Reports in the System, $2020 \ldots 10$

6. Lags in Dissemination of TA Reports___ 11

7. Dissemination Process Timeline, $2020 \_11$

8. Downloads of Fund Documents __ 15

\section{ANNEX}

I. Dissemination Policy by Information Type and Non-Fund Staff Audience 


\section{CONTEXT}

1. The dissemination and publication of the Fund's CD information needs to adapt to a changing landscape. Significant time has passed since management set forth the framework of the current dissemination policy in the 2008 framework paper and established the dissemination policy in the Operational Guidelines ("current policy"). ${ }^{1}$ The scale, scope, and nature of $C D$ have since evolved. The Fund is now delivering more CD (Figure 1), through new delivery modalities, and producing greater and more diverse types of $C D$ information products. The external landscape has also transformed, as Fund members, partners, and other $C D$

Figure 1. Capacity Development Spending (Millions of USD)

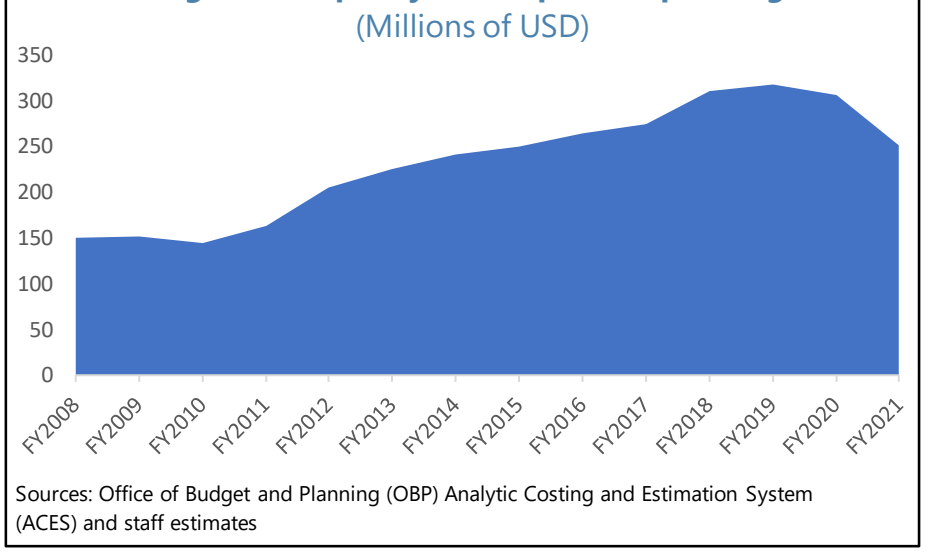
providers increasingly expect greater transparency and access to information. Recognizing these developments, the 2018 CD Strategy Review recommended enhancing information sharing and dissemination, and Executive Directors encouraged innovative approaches to raise awareness of the Fund's CD work and called for more publication while preserving confidentiality and client trust.

\section{This paper informs the Executive Board of management's intended revisions to the} current policy to widen the dissemination and publication of information. Wider dissemination and publication would yield many benefits:

- Coordination and synergies. More active and timely sharing of information with other CD providers and financing partners would mitigate the risk of siloed CD delivery, improve coordination, exploit synergies, and enable the Fund to prioritize and leverage its limited resources. Increasing dissemination of information to Fund staff, especially in area departments, supports $C D$, lending, and surveillance integration, and enhances outcomes.

- Knowledge as global public good. Through publication, the membership and the public at large could benefit from best practices in key policy areas and capacity building body of knowledge learned through the Fund's experience providing CD. Publication also showcases the Fund's contribution to the global public good.

- Accountability. The Fund has an obligation to report on work funded by financing partners and is accountable to the membership more broadly. Financing partners have a legitimate interest in receiving timely information on $C D$ they are funding to satisfy their own domestic accountability requirements. Similarly, broader and timelier dissemination of CD information, will help garner

\footnotetext{
${ }^{1}$ The Operational Guidelines were initially established in 2009 and amended in 2013 and 2020. The current Operational Guidelines can be found here.
} 
support for the Fund's work among the membership and public. Increased transparency also helps manage potential funding risks by supporting fundraising efforts.

- Ownership. Within CD recipient countries, wider and timely dissemination of information among different government agencies mitigates the risk of uncoordinated implementation of $C D$ recommendations and strengthens ownership. More generally, publication of information may also help muster domestic social and political support for reforms.

\section{These reforms seek to preserve the Fund's trusted advisor role and maintain staff candor, while taking into account the resource implication of wider dissemination. Some} information may be provided to staff on the understanding that it will be treated as confidential. Thus, any framework for wider dissemination must have appropriate safeguards to protect information. Wider dissemination should also be balanced with the risk of staff becoming less candid in their assessments and recommendations. Finally, wider dissemination, particularly via publication, may also require more staff time and resources to finalize and translate materials.

\section{The update clarifies which types of final CD outputs require consent for their} dissemination. ${ }^{2}$ As noted above, the authoring department's role as a trusted advisor implies that the advice could include information that the authoring department or the $C D$ recipient (or recipients in the case of multi-country $C D$ ) consider sensitive and therefore would like to be treated as confidential. This should however not be construed to mean that all TA advice in final CD outputs, particularly TA reports, is inherently Confidential. Such characterization could be confused with specific General Administrative Orders (GAO) classification nomenclature. Therefore, this paper and the future policy will replace the term confidential, when used in a general sense and outside the specific GAO classification, with either non-public or sensitive to characterize information that can only be made available to the public on the basis of non-objection or with explicit consent. This does not change the broad principle noted in Box 1, which is that for all types of CD information, dissemination will continue to be voluntary for both recipient and authoring department and consent requirements will hold (with ex-ante consent assumed in a limited number of circumstances).

\section{Based on the considerations set out in this paper and taking into account Executive Directors' views, management intends to amend the Operational Guidelines. The Operational} Guidelines will be circulated to the Board for information and published. The Fund's authority to provide CD is exercised by the Managing Director as part of the ordinary business of the Fund, but

\footnotetext{
${ }^{2}$ See IMF, 2008, Dissemination of Technical Assistance Information (Washington), $\$ 2$ on "the practice of treating most TA information as confidential;" Exchange of Documents with Other International Agencies-Release of Technical Assistance Reports and Modification of Procedures for Release of Documents ("Exchange of Documents with Other IA", 1/28/93) p. 2, in which staff observed: "Since its inception, technical assistance by the Fund has always been provided on a highly confidential basis." IMF, 2000, Annual Report on Technical Assistance (Washington) para. 93, stating that Fund TA is sought on a confidential basis and therefore TA recipients have the right to decide on dissemination, subject to management approval.
} 
subject to relevant Board decisions and guidance on general TA policy matters. ${ }^{3,4}$ Subject to a few exceptions, management's authority over $C D$ also extends to decisions on dissemination-including publication-of CD information. ${ }^{5}$ This paper is intended to engage Executive Directors on the direction of the new policy prior to the circulation of the revised Operational Guidelines.

\section{Box 1. Treatment of CD Information Under Fund Policies}

The 2008 framework paper informed the Executive Board of the envisaged framework for disseminating TA-related information, and the policy was set forth in the Operational Guidelines. The Operational Guidelines, most recently revised in 2020, balance the overarching goal of disseminating information more widely with the necessity of safeguarding non-public information. This is done by adhering to two consent requirements for information that is considered non-public:

- Consent of the $C D$ recipient-which could range from explicit to implicit on a lapse-of-time basis, depending on the nature of information.

- Consent of the authoring department.

While noting that $C D$ outputs are not always provided in a shareable written or recorded format (e.g., TA advice could be provided only orally), the policy enables departments and $C D$ recipients to disseminate shareable TA information.

\section{The CD dissemination policy coexists with the Fund's other policies related to specific types of information dissemination. For example:}

- Executive Board documents are covered by the Transparency Policy. These include Financial System Stability Assessments (FSSAs) and Reports on the Observance of Standards and Codes (ROSC).

- FSAP materials that are not circulated to the Board, such as Detailed Assessment Reports (DARs) and Technical Notes may be published at the authorities' request and with management consent. The AideMémoire is intended for the authorities only and is not published.

- Safeguards assessment reports are subject to a separate disclosure regime under the safeguards assessment policy.

- The Transmittal Policy governs the routine transmittal of certain types of reports (including TA reports) to certain international agencies, including the World Bank, that meet specified criteria.

- Unpublished documents and information are covered by the Open Archives Policy, which provides for their release to the public upon request and after the lapse of certain time lags.

- With respect to dissemination among Fund staff, information (including that related to TA) is classified and handled in accordance with GAO 35, Rev. 2.

\footnotetext{
${ }^{3}$ The Fund's authority to provide TA is set forth in Article V, Section 2(b) of the Articles of Agreement. The Board recognized management's authority over TA requests from members as part of the "ordinary business" of the Fund in 1991 "Reduction and Streamlining of Board Documentation," EBD/91/244.

${ }^{4}$ Examples of these general policy decisions adopted by the Board are the rules for effective prioritization of TA activities and the country contribution policy for technical assistance. See, e.g., 2018 Review of the Fund's Capacity Development Strategy and 2008 Framework Paper.

${ }^{5}$ Under GAO 35, Rev. 2, management has delegated decisions on dissemination of department-authored materials to heads of departments.
} 


\section{Box 1. Treatment of CD Information Under Fund Policies (Continued)}

- All TA-related information produced by Fund staff or Fund experts remains Fund intellectual property. Sharing Fund and any third-party intellectual property externally must follow the Fund's Copyright Policy.

The revised framework maintains the key principles of the current policy, while expanding the scope of shareable CD outputs, in particular to include training, and clarifying the treatment of certain information categories. The two consent requirements, as well as interaction with other information dissemination policies, will continue to hold. As such, shareable output from training (e.g., online training), as well as other formats of TA (e.g., recorded webinars) could only be shared with the consent of the CD recipient(s), where relevant, and the authoring department. Similarly, any such output shared externally requires the authoring department's permission to make or distribute copies of, make derivative versions of, or publicly display, perform or transmit, such works. Training materials shared outside the Fund may only be used to further the learning objectives of the training delivery. Ordinarily, information provided to the CD department in the course of $C D$ delivery can be shared with other Fund departments for program or surveillance purposes, unless the recipient explicitly requests that this not be shared. However, going forward, even if the recipient explicitly requests that information not be shared, Fund management can make a determination that the information is critical to surveillance or program purposes and can be shared with other Fund staff. This policy should be disclosed at the start of each CD engagement.

\section{ISSUES WITH THE CURRENT POLICY}

\section{The Fund has made significant progress with information sharing, but experience} since 2008 had revealed several shortcomings of the current policy. The Fund has provided financing partners and the Executive Board access to most TA reports, increased staff engagement on $C D$ with the Board, shared technical notes, manuals, and analytical tools, and launched new products for public consumption, such as Policy Issue Notes (e.g., COVID-19 and how-to-notes), as well as annual reports of regional CD centers (RCDCs). The Fund also disseminates CD knowledge through seminars, conferences, and in products such as staff working papers, flagship documents, and Article IV consultation reports. Some areas, however, remain challenging. Given the length of time elapsed since the current policy was drafted and the significant growth of $C D$, in both volume and delivery modalities, gaps have emerged in the coverage of the existing policy. Additionally, publication rates of TA reports remain low, the burden on staff resources for disseminating and publishing CD information has risen, and additional clarity is needed for dissemination of some information categories.

\section{A. Some Types of CD Output are Not Covered by the Current Policy}

\section{CD has evolved since the current policy was originally drafted. The 2008 framework} paper was drafted before the Fund conceptualized $C D$ to cover both TA and training. Training, which accounts for 14 percent of all CD delivery, produces shareable output, that funding partners may request for accountability purposes, other providers may find useful for their own delivery (provided appropriate copyright rules are respected), or the public may benefit from. Additionally, new modalities of CD delivery introduced over the years, such as online training in FY14 (Figure 2) and 
virtual CD in FY21 (Figure 3), have resulted in newer formats, such as recorded webinars and workshops.

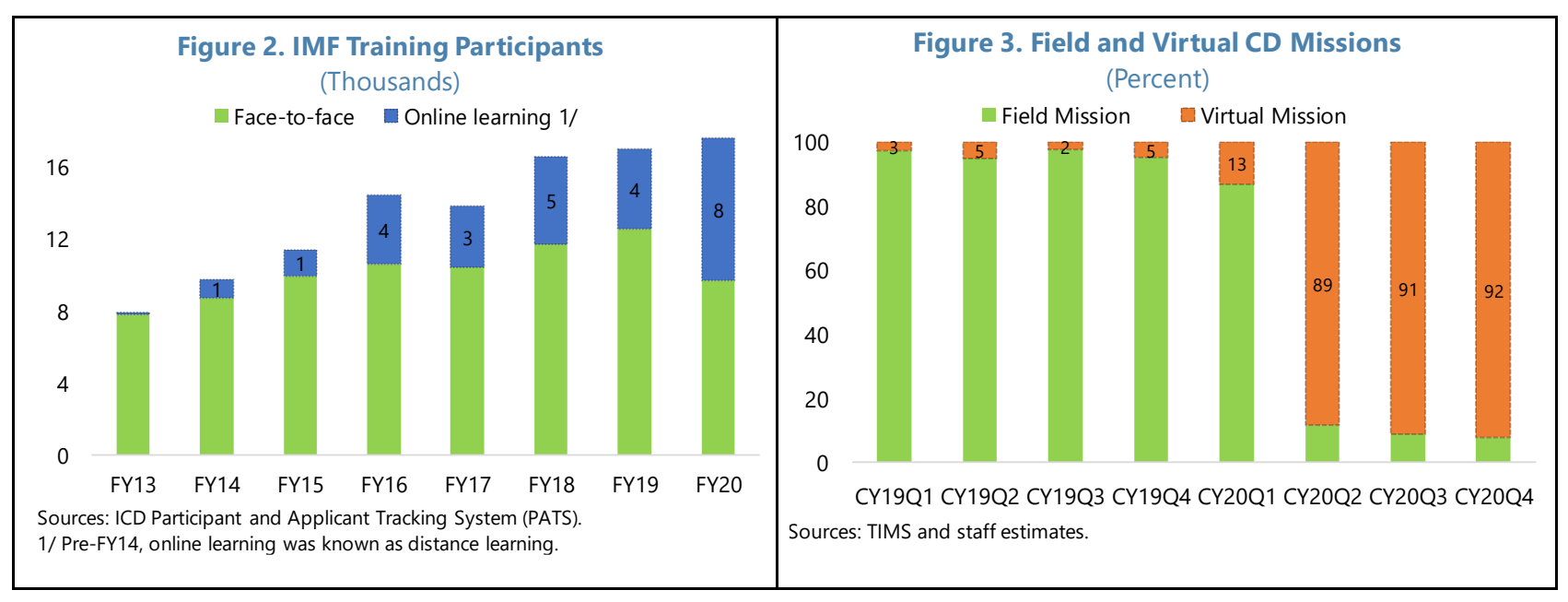

8. The current policy no longer fully captures the wide array of shareable output. CD output refers to any shareable (e.g., written or recorded) output of CD provided by IMF staff. Under the current policy, there is no clarity on how CD outputs other than TA reports could be disseminated. Although TA reports will continue to be the most common shareable CD output, the dissemination of training output, such as recorded workshops, PowerPoint presentations, and models can improve CD delivery coordination, support accountability, as well as support the Fund's contributions to global public knowledge.

\section{B. Publication Rates of Final TA Reports Remain Very Low}

\section{The current policy recognizes the importance of publishing final TA reports, as part of} the broader objective of wider dissemination. In particular, the Operational Guidelines noted that staff should proactively encourage TA recipients to agree to publication of TA reports by the Fund, recognizing that these have been the main vehicle through which TA advice is conveyed. The relevance of TA report publication was affirmed by the Executive Board during the 2018 CD Strategy Review.

\section{However, publication of final TA reports}

remains low. Over the last three years, the Fund published only an average of about 7 percent, or around 62 out of the 964 TA reports annually uploaded in the Institutional Repository (IR) (Figure 4). ${ }^{6}$

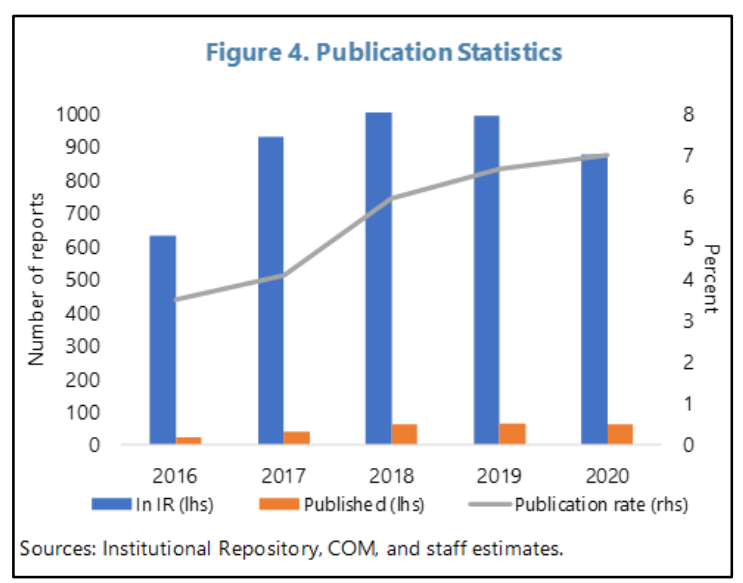

\footnotetext{
${ }^{6}$ The number of reports in the IR may underestimate the total number of reports produced, especially in earlier years, given problems with IR submission (\$14). Using the number of reports in Electronic Document Management System (EDMS) as the denominator lowers the publication rate slightly (in 2020, from 7 to 6 percent).
} 
In contrast, staff reports for Article IV consultations or the use of Fund resources (UFR) have a publication rate of around 96 percent while publication rates of Financial Sector Stability Assessment reports and technical notes are around 90 and 50 percent, respectively. While the Fund has produced new products such How-to-Notes, low publication rates of TA reports impact on the Fund's ability to contribute to knowledge as a global public good, as well as support coordination and synergies.

\section{Several factors explain the low publication rate.}

- Consent requirements are time-consuming, and the CD recipient(s) may have concerns around the publication of sensitive, non-public information. Publication of final TA reports requires the explicit consent of the $C D$ recipient(s), as well as the approval of the head of the authoring $C D$ department, in consultation with the relevant area department. While the latter has not typically been a barrier, obtaining explicit (i.e., written) consent from the CD recipient has been challenging. While authoring departments could exert more effort to obtain consent, it is also possible that the $C D$ recipient(s) may simply not wish to publish the report in its entirety if it contains sensitive, non-public information or highlights gaps in domestic frameworks or capacity.

- Publication can be administratively onerous and resource intensive. Even after obtaining explicit consent, the process and internal systems do not always support prompt publication. First, current policy requires that TA reports be circulated to the Executive Board for information in advance of publication. The process adds an extra step and requires staff to resubmit the report through a separate internal document processing system, despite having been submitted to the IR already. Second, as the working language of the Fund is English, all non-English TA reports that are planned for publication (approximately 15 percent of published reports) must be translated before circulation to the Board, requiring additional resources.

\section{Revisiting the Corrections and Deletions Rules}

\section{The final review process for TA reports prior to publication is unnecessarily}

cumbersome. The TA recipient has an opportunity to review a TA report in a two-step process. First, prior to finalization the authoring department consults the $C D$ recipient over the draft report, soliciting their feedback, including on any corrections. The report is modified as needed, finalized, and transmitted to the $C D$ recipient. Second, when requested to consent to publication following transmittal of the final report, the CD recipient can request further corrections and deletions for a narrow list of reasons outlined in the Operational Guidelines. ${ }^{7}$ This happens in practice in a very small number of cases (around 10 percent of reports) where the CD recipient consents to publish. In these cases, the process for corrections and deletions can be burdensome. In particular, after

\footnotetext{
${ }^{7}$ Corrections are permitted for (i) data or typographical errors; (ii) factual mistakes; and (iii) mischaracterization of views expressed by either, the TA recipient, or by Fund staff from departments in the context of the internal review process. Deletions may be proposed to management by the TA recipient, provided the relevant material is not already in the public domain and qualifies as (i) highly-market sensitive information; or (ii) policy intentions whose premature disclosure would seriously und ermine the ability of the TA recipient to implement the proposed policy.
} 
transmittal of the report to the CD recipient any changes require a departmental review and Fund management approval. Management approval and departmental review are designed to ensure evenhanded application of the criteria of what can be corrected or deleted to the narrow circumstances allowed under the policy.

\section{Delays and Gaps in Dissemination of Final TA Reports}

\section{The dissemination of final TA reports to staff, Executive Directors, and funding} partners has been more successful, but challenges remain. The majority of TA reports are available to staff, Executive Directors, and financing partners with access facilitated by digital applications. The IR surfaces these reports on Knowledge Exchange (KE) country pages for easier staff access and channels them to Executive Directors and financing partners (via Partners Connect). In 2020, around 80 percent of the reports stored in the internal document system (EDMS) have been uploaded to the IR (Figure 5). Some TA reports are Strictly Confidential and therefore not submitted to the IR per current policy. ${ }^{8}$ However, a significant

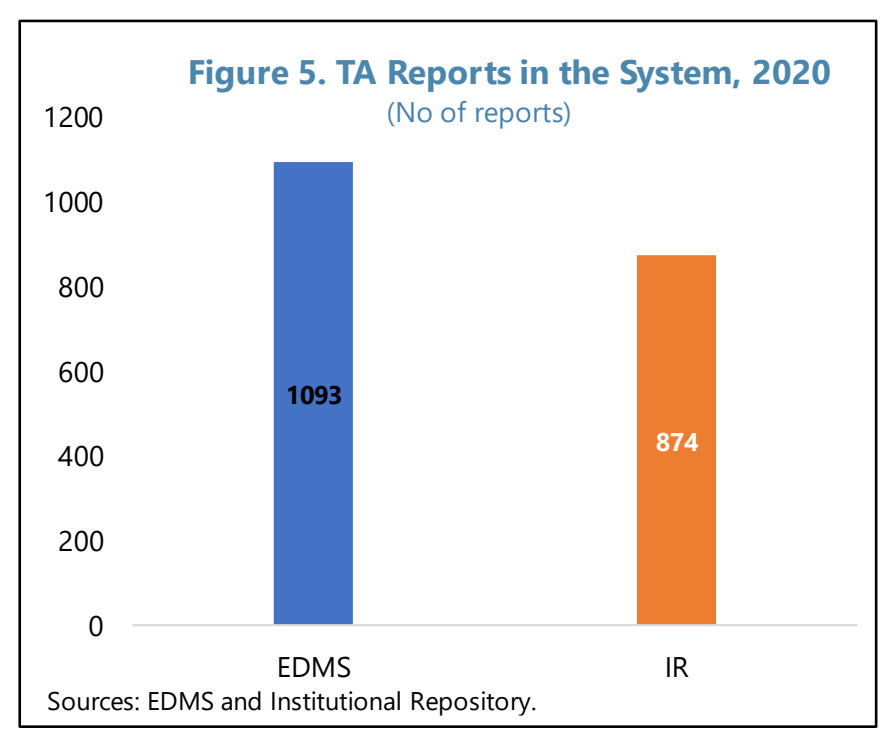
portion of reports that should be available still fall through the cracks and are therefore not disseminated (โ14). Moreover, under the general principle that staff may not disclose information that a member or other person has provided in confidence unless that party consents to disclosure, CD departments may not share information obtained in the course of CD delivery with staff in other departments (e.g., area departments), if the $C D$ recipient explicitly requests such dissemination be limited, which hinders the integration of $C D$ with surveillance and lending.

\section{Several factors account for gaps in the dissemination and publication of TA reports} and other outputs. There is no consistent practice across authoring departments regarding the dissemination process, particularly on submitting reports produced in regional technical assistance centers (RTACs) to the IR. As a result, some RTAC reports may be in EDMS, but not in the IR. Moreover, inefficiencies and gaps in the document/repository systems which require multiple separate submissions for a single TA report also create an administrative burden and operational risk. Finally, there is limited guidance on sharing other types of final TA output (e.g., presentations, Aide Mémoires).

\footnotetext{
${ }^{8}$ In the current policy, TA reports classified as "Confidential" are reclassified automatically "For Official Use Only" after two years, unless the authoring department or the relevant area department considers that the sensitivity of the information has not diminished.
} 


\section{Moreover, dissemination is not always timely, which undermines its effectiveness.}

In 2020, TA reports submitted to the IR took an average of over three months to be finalized and transmitted to the $C D$ recipient from the end of mission, and a further six months to be submitted to the IR (Figure 6). Reports are therefore only posted on KE country pages, as well as shared with Executive Directors and financing partners, on average nine months after the end of a mission. This reduces the potential benefits of learning from peer country experiences, limits buy-in, hinders coordination efforts

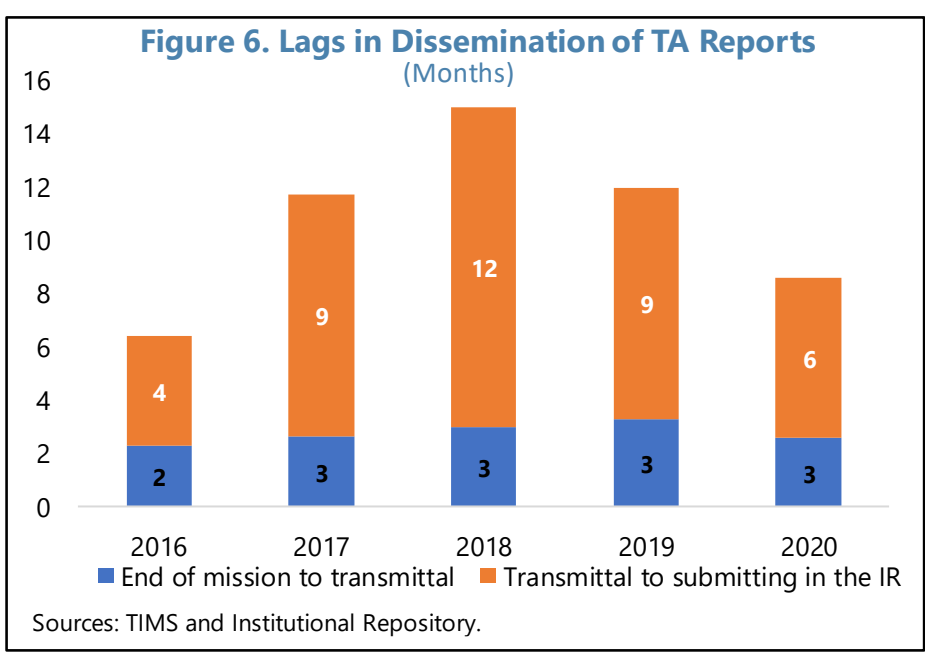
among providers, and undermines the Fund's internal CD and surveillance integration efforts.

\section{There is no Fund-wide standard on timely TA report finalization and submission to the}

IR. Many departments have internal policies requiring reports be finalized and transmitted to the CD recipient around 6 to 7 weeks from the end of mission. The three-month average lag however suggests that this is often not followed. Moreover, while the current policy requires all TA reports to be submitted to the IR, it does not set any expectation on when it needs to be done, resulting in long lags (Figure 7).

\section{The time needed to obtain a CD recipient's consent on a non-objection basis after} finalizing the report also reduces timeliness. The current policy provides for $C D$ recipient's consent on a 60-day lapse-of-time basis when sharing final TA reports with Executive Directors and members of their staff, financing partners, as well as other parties with legitimate interest, including other agencies or instrumentalities of the member country receiving the $C D$.

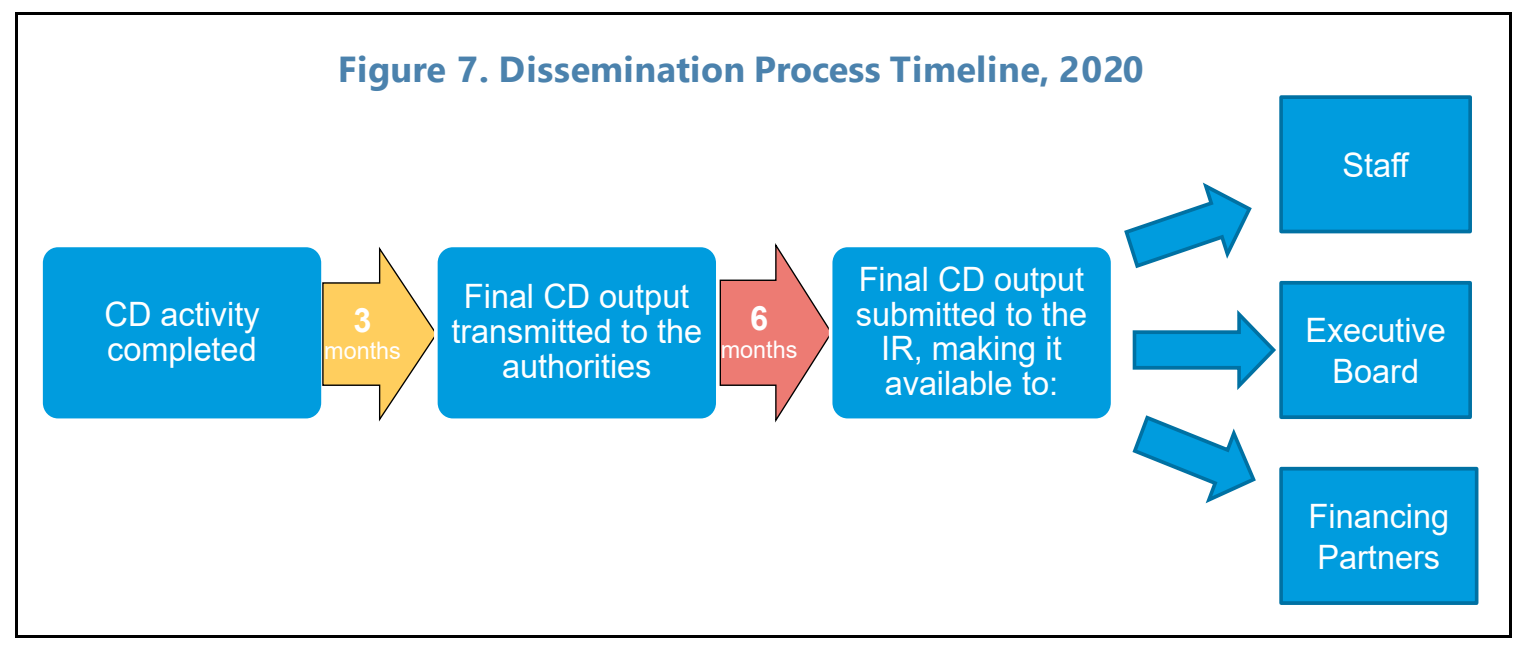




\section{E. Lack of Clarity Over Other Types of CD Information}

\section{Enhanced CD management practices and IT systems have led to an expansion of} certain information types. The introduction of Results Based Management (RBM) in 2013 created project-specific log frame data, including country-specific ratings of outcomes, indicators, and milestones. The subsequent approval of the Common Evaluation Framework in 2016 and its update in 2020 linked RBM information to evaluations. Administrative information further expanded and became linked with other operational and financial data with the introduction of the internal operational system for CD, CDMAP, in 2021. Finally, more broadly applicable products without CDrecipient-specific information have emerged.

\section{Assessment Information}

\section{Current policies and practices for sharing the growing amount of CD assessment information are not sufficiently specific and are applied unevenly.}

- Evaluations. Evaluations are systematic and objective assessments of ongoing or completed CD interventions. They follow the Common Evaluation Framework and are conducted by external experts or Fund staff not associated with the CD being evaluated. Evaluations are considered "administrative information" under the current policy (unless they contain final CD advice and CD recipients' performance against the advice), and therefore generally could be freely disseminated and published. However, in practice, IMF02-funded evaluations are shared with the relevant funding partners, but not Executive Directors. IMF02-funded evaluations of RTACs are publicly available via RTAC websites, but not evaluations of thematic funds or bilateral projects, nor are IMF01-funded internal evaluations. The recently approved Common Evaluation Framework laid out new policies on the dissemination of evaluations, requiring CD recipient consent for sharing with Executive Directors and the public if the $C D$ recipient's country is mentioned in the main report (shared with funding partners; 60-day lapse-of-time for Executive Directors; explicit consent for the public). This policy applies only to evaluations that started after August 2020.

- RBM. RBM assessments are informal assessments, generally produced by the individual or team delivering CD. RBM data do not cleanly fit into an information category under the current policy. The RBM Governance Framework recently filled the gap, by requiring CD recipient consent for dissemination of country-level RBM information beyond staff (60-day lapse-of-time for dissemination to Executive Directors and funding partners; explicit consent for the public).

- Other CD delivery assessments. Like RBM, other types of assessments, such as annual project assessments (which are a project manager's evaluation of project progress and include information about project risks and results), do not fit in an information category under the current policy. In practice, project assessments are shared with financing partners, but not with Executive Directors. In the past, they were not systematically shared internally among staff, although CDMAP will make this information more readily available. 


\section{Administrative Information}

20. The current policy for disseminating information related to the administration of CD projects ("administrative information") does not explicitly address interactions with new internal operating systems. Administrative information is generally defined as information related to the management of $C D$ and includes, but is not limited to, project budgets, funding sources, personnel engaged in delivery, and funding program proposals. The current policy generally does not consider administrative information to be sensitive or non-public, unless the $C D$ recipient specifically requests otherwise at the time of the request for $C D$. It therefore allows the broad dissemination and publication of administrative information. The policy, however, does not provide specific guidance about sharing raw information directly through internal operating systems, such as CDMAP. This raw information may be attached to other types of internal operational information that cannot be shared outside Fund staff, such as information from the travel management system (TIMS) and the financial system (FINPROD).

\section{Non-CD-Recipient or Non-Country-Specific Information}

21. The current policy does not explicitly state how non-CD-recipient-specific or noncountry-specific CD information should be managed. The information categories outlined in the current policy assume CD-recipient-specific or country-specific information, and therefore discussion of how these information categories should be treated is focused on recipient consent. ${ }^{9}$ However, CD information of any category could be more generic. Examples include, but are not limited to, policy issue notes such as COVID-19 or how-to-notes (final CD output), non-CD recipient training materials (final CD output), regional evaluations without country-specific information (assessment), and aggregated RBM data by region and workstream (assessment). Clarity on how more generic forms of information should be treated is needed as the Fund continues to produce more of these types of products.

\section{PLANNED POLICY REFORMS}

\section{Management intends to widen the scope of dissemination of information under the} revised policy, while balancing staff and CD recipients' concerns around candor, trust, and resources. These reforms have benefitted from internal deliberations, through focus groups and interdepartmental consultations.

\footnotetext{
${ }^{9} \mathrm{CD}$ recipients could include entities within member country authorities, non-member country authorities, or regional and multinational bodies (e.g., CEMAC). In the case where the CD recipient is an entity within a country authority, $C D$ recipient-specific information includes references to both the country and the specific entity. In the case where the $C D$ recipient is a regional or multinational body the term, $C D$ recipient-specific includes references to the regional or multi-national bodies. Country-specific information includes references to all countries, even if they are not $C D$ recipients.
} 


\section{A. Expanding the Scope of the Policy}

\section{The planned reforms broaden the scope and the current definition of final TA advice.}

First, a new category, called final CD output, would replace the current category of "final TA advice." The main purpose here is to bring training outputs under the policy. Second, with respect to both TA and training, the revised policy will be more granular regarding specific shareable outputs. Final CD outputs would include any shareable (e.g., written or recorded) output of CD provided by Fund staff (whether TA or training) in the final form delivered to the CD recipient(s). This category would include final forms of advice or recommendations found in final TA reports, models, tools, webinars, and training videos conveyed by Fund staff to the recipient(s) during TA or training delivery. This information type could be provided to $C D$ recipients via any modality and in any format, including TA reports, presentations, recorded events and notes. Just like final TA advice under the current policy, final CD output is presumed to contain sensitive, non-public information, therefore requiring the consent of $C D$ recipients and staff prior to dissemination/publication.

\section{The new category of final CD output will include training outputs, which may be} disseminated. The authoring department will be responsible for determining whether the shareable output (e.g., presentations, recorded events) is final. ${ }^{10}$ In some cases, the shareable output could be training aides (e.g., slides, worksheets) that need accompanying (but often non-shareable) context and explanation from the instructor to be considered as final output. The authoring department will have discretion in determining which training outputs will be disseminated as final CD outputs. Online training or recorded webinars, which combine both training aides and instructor explanation, are examples of training output which authoring departments may consider final CD output and can therefore be disseminated. Dissemination of final training outputs would normally occur via the Fund's website.

\section{B. Raising Publication Rates of Final CD Output}

25. The reforms aim to increase publication rates, while taking into account resource implications and CD recipient confidentiality considerations. On average, close to 1,000 TA reports are produced every year, compared to fewer than 200 Article IV or UFR reports. The policy therefore must take into account the resource implications of increasing publication rates. Moreover, the policy must prevent the publication of information without the CD recipient's consent.

\section{The planned policy will envisage the publication of high-level summaries of strategic} final CD output. Strategic final CD output comprises content that reflects broad recommendations from a CD project, including training, often diagnostic or aimed at significant reforms, as opposed to more specific, operational, and technical advice. The authoring department will determine which final CD output they consider strategic, based on the guiding principles that will be laid out in the Operational Guidelines. Some examples of strategic output include output providing a general

\footnotetext{
${ }^{10}$ As the institutional manager of the Institute Training Program (ITP), ICD will also provide consent, along with the authoring department, before CD output associated with ITP courses can be shared outside the Fund.
} 
diagnostic of the tax system, or reports on strengthening the legal framework for deposit insurance and bank resolution, establishing a macroprudential policy toolkit, and rebasing GDP. For all strategic final CD output, a high-level summary should be prepared by staff. The following are specific features of the policy:

- A high-level summary would include the broad objectives, findings, and recommendations of the $C D$. In the case of training, high-level summaries should outline training objectives, and if applicable any good practices, recommendations, and advice. They should be drafted with sufficient context to mitigate the potential risk of content or advice being misunderstood or misconstrued. In the case of TA reports, summaries would normally reproduce executive summaries from the full output to minimize additional work.

- The CD recipient's consent to publish a summary would be requested on a lapse-of-time basis with 20 business days from the transmittal of the summary and final output. As is the norm for TA reports under current policies, the CD recipient will have the opportunity to review a draft of the summary before the final transmission. The authoring department will inform recipients of this policy at the start of the project and when sending the draft.

- The final CD output (e.g., TA report) may be published with the CD recipient's explicit consent, as under current policy. Authoring department approval will continue to be required.

- The authoring department will have discretion as to the production and publication of high-level summaries of strategic final CD outputs if they are classified as Confidential and Strictly Confidential in accordance with GAO 35, rev. 2.

\section{High-level summaries of strategic} final CD output will address some of the factors that hinder broader publication. The summaries would not reveal the detailed technical analysis underpinning the final recommendations and therefore will be less likely to contain potentially sensitive information and less likely to impinge on the Fund's candor and trusted advisor role. Seeking consent on a lapse-of-time basis will facilitate more and timelier publication. Moreover, focusing on strategic documents, including training outputs,

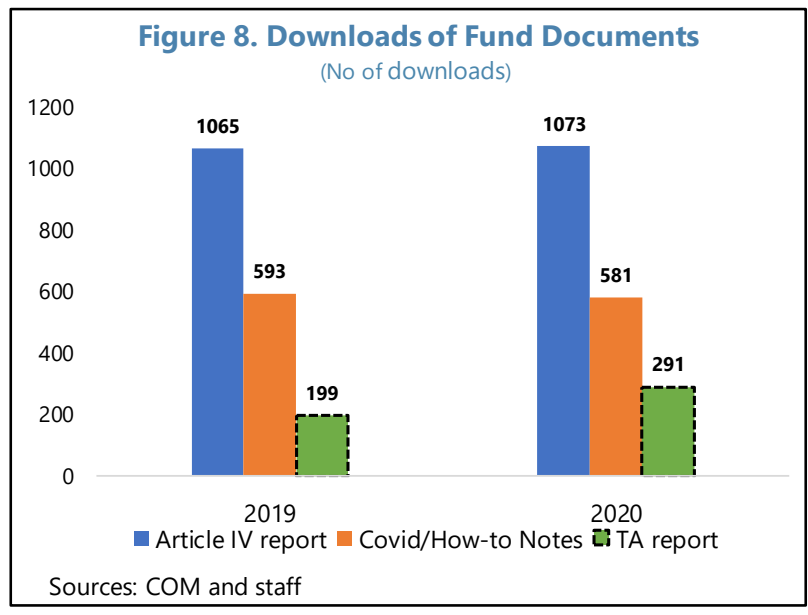
will yield more extensive peer learning and impactful dissemination of good practices, while reducing resource implications. Many TA reports already include executive summaries, that could be repurposed for publication purposes. Finally, high-level summaries may be more accessible to nonexperts and the general public. Comparing average downloads of Fund documents reveals that policy issue notes (COVID-19, how-to-notes) and Article IV reports are downloaded in larger numbers than are TA reports (Figure 8). This may be in part due to the latter's more technical nature 
and specialized audience, although policy issue notes and Article IV reports do have regional and global scope and are often supported by their own communications campaign.

\section{The reforms aim to reduce administrative burden while maintaining adequate Board} access. The updated policy removes the requirement to circulate full final CD output, including high-level summaries, to the Executive Board in advance of publication. This removes the need to translate non-English reports into English, freeing up staff resources and facilitating greater publication of CD output in languages other than English. Note that this approach would not reduce Executive Directors' access to information. All final CD output of the constituency-whether for publication or not-would be made available to the pertinent Executive Director, as soon as they are transmitted to the $C D$ recipient, unless the $C D$ recipient objects. As with Fund working papers, the Executive Director of the country of the $C D$ recipient will be notified before a final $C D$ output is published. Other Executive Directors would also have access to final output not classified as Confidential or Strictly Confidential after the lapse-of-time consent process (where the CD recipient does not object to dissemination), not just final outputs lined up for publication.

\section{Limiting Post-Transmittal Modifications}

29. The planned reforms aim to expedite publication of final CD output. As per existing practice, the $C D$ recipient should be consulted for feedback over the draft report, including highlevel summaries, in advance of finalization. Following these consultations, as well as the internal review process, the finalized $C D$ output, including high-level summaries, would be considered final and transmitted to the $C D$ recipient. In a change from the current policy, no post-transmittal modifications of final CD output, including high-level summaries, would be permitted, except for corrections for remaining typographical errors which can be made by staff following each department's internal process and without a memo to management. Deletions of market-sensitive information will not be permitted post-transmittal, and the expectation is that reports containing such information will no longer be published. The planned policy reduces administrative burden, at the expense of potentially fewer published full final CD output. Moreover, keeping the CD recipient's explicit consent as a requirement for publishing the full CD output and shifting the expectations of publication to high-level summaries (which only requires obtaining consent on a non-objection basis) protects the candor between $C D$ provider and recipient.

\section{Increasing the Timeliness and Coverage of Dissemination of CD Information}

30. The planned reforms aim to enhance the timeliness and coverage of dissemination. A key goal is to increase the timeliness of dissemination by reducing the time between the end of the relevant activity or mission and the transmittal of the final $C D$ output to the $C D$ recipient; and narrow the gap between transmittal to the $C D$ recipient and submission to internal document systems, including the IR. Supporting the integration of CD with surveillance and lending, the new policy would also put CD recipients on notice that management, in very limited circumstances, may 
authorize sharing with staff, with a strict need to know, information obtained by CD departments during $C D$ delivery, even if the $C D$ recipient explicitly requests sharing among staff to be limited.

\section{The planned policy would introduce internal norms on the finalization of all final CD} output. Fund-wide indicative norms stipulate that all final CD output, including high level summaries, are expected to be (a) transmitted to the $C D$ recipient within 30 business days from the last day of the activity (some activities, such as diagnostics, will take place and end before the overall $\mathrm{CD}$ project concludes and training is transmitted at the time the training is conducted); and in the case of written output (b) marked as final in the internal document system (EDMS, or its replacement) and, (c) if applicable, submitted to the IR within three days from the transmittal to the CD recipient. ${ }^{11}$ Aside from setting expectations, these norms would facilitate monitoring and help identify remaining impediments to dissemination. In addition, staff will be working on specific procedures, around other types of final CD output (beyond TA reports and high-level summaries) to ensure that they are as readily available as TA reports to all staff and to facilitate their dissemination to Executive Directors and financing partners.

\section{The planned policy changes will simplify consent processes for final CD output to} speed up dissemination. $C D$ recipient lapse-of-time consent to share final $C D$ output with financing partners, Executive Directors, and other parties with legitimate interest would be reduced from 60 days to 20 business days from transmission of the final output. Given the ease of modern electronic communications and general practice of sharing draft reports in advance of finalization, a 20-business day lapse-of-time is considered reasonable and will serve as the lapse-of-time period to obtain consent for dissemination. This reform allows for sharing of final CD output in a timelier manner, supporting increased coordination and supporting accountability needs of financing partners.

\section{The planned policy changes will enable the sharing of information obtained during CD} delivery by CD departments with relevant Fund staff in other departments to support the closer integration of $C D$ with surveillance and lending, even if the $C D$ recipient requests sharing among staff be limited. ${ }^{12}$ The default policy position is that information received by Fund staff in the course of $C D$ delivery can be shared with other Fund staff in line with GAO classification policies, unless explicitly requested by the CD recipient not to do so. Under the proposed policy, where $C D$ recipients request information sharing among staff be limited, management can decide to share the information with relevant staff in the area and functional department(s) if it deems the information critical for program or surveillance purposes. In this case, the assumption is that CD has been provided on the explicit understanding that, by requesting $C D$ from the Fund, recipients have provided irrevocable consent that information considered critical for program or surveillance purposes by Fund management may be shared with the relevant departments. For avoidance of doubt, $C D$ departments may not reach ex-ante understandings that non-public information will be

\footnotetext{
${ }^{11}$ Submission to the IR allows immediate access by Fund staff. Direct financing partners and Executive Directors will only obtain access if no objection is received from the CD recipient 20 business days after transmittal (\$32).

${ }^{12}$ Given the need to backstop and supervise CD provision, individuals providing CD may not agree to keep information from their managers, up to the Managing Director.
} 
withheld from other departments. This information should be classified appropriately according to GAO 35 rev. 2. CD departments are expected to communicate this policy to the CD recipient at the start of the engagement. This change is intended to ensure the appropriate integration of $C D$ and surveillance activities, and also that critical information in the hands of Fund staff, is made available to departments involved in program and surveillance work. Sharing such information with the Executive Board will continue to require explicit consent from the CD recipient. ${ }^{13}$

\section{E. Clarifying Policy for Existing CD Information Types}

34. Greater clarity is required on the dissemination of certain information types that have changed over the years. In particular, CD information not tailored to a specific recipient does not fit neatly into the existing policy. Further, the Fund's assessment information has grown more complex to meet internal and external accountability and project management needs, with disparate guidance. The creation of a single category of "assessment information" should assist staff in understanding dissemination rules. Similarly, while the rollout of CDMAP has not changed what "administrative information" is, the new policy needs to articulate clearly how new types of administrative information impact dissemination practices.

\section{Non-Recipient- or Non-Country-Specific Information}

\section{Any of the information types outlined in the CD dissemination policy can include content produced by the Fund that does not list details specific to a CD recipient or country.} Non-recipient or non-country-specific information (e.g., RBM ratings aggregated by region) can support coordination and synergies and contribute to knowledge as a global public good. As a general rule, given that $C D$ recipients are not identifiable, staff sees no reason why this could not be disseminated and published. Authoring departments would retain discretion as to what nonrecipient- or non-country-specific information they would want to disseminate and through which channels.

\section{Assessment Information}

\section{The planned policy will create a new category of information to capture the Fund's} assessments of CD provision (including evaluations). Information produced by Fund staff or contractors (e.g., evaluators) related to performance, results, and progress of delivery during the planning and management of $C D$ in the course of the Fund's assessment of CD provision will generally be available for dissemination, subject to the consent requirements elaborated below. This information category includes RBM data, internally and externally (e.g., donor) funded evaluations, project risk assessments, and project assessment reports. A single category capturing this type of information would enable consistent practices and address existing gaps.

\footnotetext{
${ }^{13}$ Where management is of the view that confidential information needs to be disclosed to the Board (for example, in order for the Board to make an informed decision on a program review or to conduct effective surveillance), the appropriate course of action would be for management not to recommend Board action unless the information provider consents to disclosure.
} 
37. Country-specific assessment information is considered non-public. This information can be made available to direct financing partners and Executive Directors. CD recipients should be explicitly informed of this policy at the start of each engagement and are presumed to have consented to dissemination of assessment information to direct financing partners and Executive Directors. ${ }^{14}$ The dissemination of such information to other parties with legitimate interest would however require the $C D$ recipient's consent, which would be requested on a lapse-of-time basis. ${ }^{15}$ Dissemination to the public will require explicit consent. As noted already, dissemination of assessment information not specific to a $C D$ recipient or country does not require recipient consent ( $(135)$.

\section{Administrative Information}

\section{As is the case with the current policy, administrative information will continue to be} made available, unless a CD recipient explicitly requests not to. The revised policy will explicitly cover administrative information in the CDMAP system. CDMAP is an internal operational system, and information captured within the system, including administrative information related to $C D$ projects, can only be accessed directly by licensed Fund staff. Administrative information, including members specific information (for example, project-level budgets, mission dates, and project-level funding sources) may be disseminated to Executive Directors or outside the Fund, unless the CD recipient has explicitly requested that such information not be shared. As general practice, staff are expected to provide sufficient context when sharing administrative information to support proper interpretation.

\section{Other Information Categories which are not Changing}

39. The policy will remain the same for recipient-specific CD information falling into the other information categories. These include "the fact and subject matter of CD," and "information that forms the basis of final CD output." The fact of provision of Fund CD in response to a particular request and the general subject matter of that $C D$ is not considered non-public information, unless the $C D$ recipient specifically requests otherwise at the time of the request for $C D$. Therefore, it would ordinarily be made available to the public, Executive Directors, and to other providers and financing partners upon request. Information that forms the basis of final CD output, on the other hand, is considered non-public and requires explicit consent by the $C D$ recipient to be shared. This applies to two different types of information within this category: (a) information provided by the CD recipient or third parties in the context of the provision of Fund $C D i^{16}$ and $(b)$ information generated by Fund staff in the course of provision of $C D$ before the $C D$ output is finalized. Such information can only be

\footnotetext{
${ }^{14}$ For ongoing $C D$ projects initiated before the new dissemination policy becomes effective, the CD recipient should be informed about the new policy before commencing a new activity, including how the CD information will be treated henceforth.

15 The authoring department in consultation with the relevant area department must determine that the donor or CD provider has a legitimate interest. Other parties with a "legitimate interest" include) a do nor or CD provider engaging in related activities in the $C D$ recipient country in the subject matter of the Fund's $C D$.

${ }^{16}$ Where information has been received from a third party, the explicit consent of such party will also be required prior to the dissemination of the relevant information.
} 
shared outside the Fund where such sharing is considered necessary to facilitate coordination with financing partners and other providers and to exploit synergies.

\section{Interaction with the World Bank}

\section{The policy on sharing final CD output and information that forms the basis of final CD output with the World Bank will remain largely unchanged. ${ }^{17}$}

- As under current policy, Fund staff may share final CD output, including high-level summaries, with World Bank staff upon request without obtaining CD recipient's explicit consent. As part of the Concordat on Bank-Fund collaboration, Fund members have been placed on notice that final $C D$ output will be shared with Bank staff. Members request Fund CD with the full knowledge of these rules and are presumed to have consented to such disclosure. However, the CD recipient can explicitly request that information not be shared with the Bank. Fund staff also retain discretion as to whether any final CD output should be shared with Bank staff.

- The World Bank will treat information in the same way that the Fund treats the information, taking practical steps to safeguard its confidentiality.

- Fund staff may also share information that forms the basis of final CD output with World Bank staff upon request, with the CD recipient's explicit consent, if the authoring department has made the determination that sharing is considered necessary to facilitate coordination and to exploit synergies.

\section{On sharing new information types, such as assessment information, as well as joint} products, with the World Bank, the proposed policy would provide greater clarity.

- Fund staff may share assessment information with World Bank staff upon request without obtaining recipient's explicit consent. However, the CD recipient may explicitly request such information not be shared with the Bank. CD recipients will have an opportunity to explicitly withdraw consent at the start of an engagement ( $₫ 42$, bullet 1$)$.

- Information produced jointly with the World Bank can be disseminated based on the more stringent rules that apply if dissemination policies differ between the Fund and the Bank (or other partner institution).

\footnotetext{
${ }^{17}$ IMF and the World Bank, Guidance Note on Information Sharing Between IMF and World Bank Staff, February 2022.
} 


\section{IMPLEMENTATION}

\section{Revisions to the policy will be communicated to the Fund's CD stakeholders.}

- CD recipients will receive a fact sheet covering the Fund's dissemination policies and practices, including $C D$ recipients' right to consent and how their information is protected, changes in policy, and the introduction of the high-level summaries for strategic CD output.

- The policy and fact sheet will be shared at the start of every CD project and mission (e.g., attached to a positive response from the Fund to a CD request from the authorities).

- $\quad C D$ departments are expected to remind CD recipients of these policies whenever final products are transmitted to the $C D$ recipient.

- The revised policy and fact sheet will be circulated to the Executive Board for information.

- Financing partners will receive a fact sheet related to the Fund's dissemination policies and practices before funding agreements are finalized.

- Other parties with legitimate interest will receive a fact sheet related to the Fund's dissemination policies and practices when requesting $C D$ information.

- The revised policy and fact sheet will be posted on IMF.org.

\section{The proposed reforms will have some resource implications, which will partially be} offset through streamlining. Increasing publication, even though the introduction of the shorter high-level summaries, will require additional resources. However, focusing on strategic output, limiting the length of summaries and, when possible, leveraging TA report executive summaries will reduce the potential workload. Additionally, efficiencies gained through streamlined post-transmittal modifications, reduced administrative requirements, eased consent requirements, shorter processing norms, and the forthcoming system improvements will help balance the potential resource costs of increased publication. Departments are expected to accommodate any modest resource costs within existing envelopes. 


\begin{tabular}{|c|c|c|c|c|}
\hline Information & Executive Board & $\begin{array}{l}\text { Direct Financing } \\
\text { Partners }\end{array}$ & $\begin{array}{l}\text { Other Parties with } \\
\text { Legitimate Interest }{ }^{1}\end{array}$ & Public \\
\hline $\begin{array}{l}\text { Fact and subject matter of } \\
\text { CD } \\
\text { (₫39) } \\
\text { May be made public, } \\
\text { unless CD recipient } \\
\text { requests otherwise }\end{array}$ & Available & Available & Available & Available \\
\hline $\begin{array}{l}\text { Administrative } \\
\text { (e.g., CD project budget, } \\
\text { personnel engaged in CD } \\
\text { delivery, final funding } \\
\text { program proposals, etc., } \\
\text { ( }(\pi 38) \\
\text { May be made public, } \\
\text { unless CD recipient } \\
\text { requests otherwise }\end{array}$ & $\begin{array}{l}\text { Available, with } \\
\text { appropriate context } \\
\text { when sharing }\end{array}$ & $\begin{array}{l}\text { Available, with } \\
\text { appropriate context } \\
\text { when sharing }\end{array}$ & $\begin{array}{l}\text { Available, with } \\
\text { appropriate context } \\
\text { when sharing }\end{array}$ & $\begin{array}{l}\text { Available, with appropriate } \\
\text { context when sharing }\end{array}$ \\
\hline $\begin{array}{l}\text { Assessment of CD provision } \\
\text { (e.g., country-specific } \\
\text { RBM data, country- } \\
\text { specific evaluations, CD } \\
\text { project risk assessment, } \\
\text { etc.,) ( }(136-37) \\
\text { Non-public }\end{array}$ & $\begin{array}{l}\text { Made available with CD } \\
\text { recipient implicit consent } \\
\text { and appropriate context } \\
\text { when sharing RBM }\end{array}$ & $\begin{array}{l}\text { Made available with } \\
\text { CD recipient implicit } \\
\text { consent and } \\
\text { appropriate context } \\
\text { when sharing RBM }\end{array}$ & $\begin{array}{l}\text { Made available with CD } \\
\text { recipient consent based } \\
\text { on a } 20 \text {-business day } \\
\text { lapse-of-time and } \\
\text { appropriate context } \\
\text { when sharing RBM }\end{array}$ & $\begin{array}{l}\text { Made available with } \\
\text { explicit CD recipient } \\
\text { consent and appropriate } \\
\text { context when sharing RBM }\end{array}$ \\
\hline
\end{tabular}

Compared with other parties with legitimate interest, World Bank staff have greater access to Fund CD-related doc ments. The Concord obtaining CD recipient's explicit consent. Members request Fund CD with the full knowledge of these rules and are presumed to have implicitly consented to such disclosure. 


\begin{tabular}{|c|c|c|c|c|}
\hline Information & Executive Board & $\begin{array}{c}\text { Direct Financing } \\
\text { Partners }\end{array}$ & $\begin{array}{l}\text { Other Parties with } \\
\text { Legitimate Interest }\end{array}$ & Public \\
\hline $\begin{array}{l}\text { Information forming the } \\
\text { basis of final CD advice } \\
\text { ( }(39) \\
\text { Non-public }\end{array}$ & $\begin{array}{l}\text { Made available with } \\
\text { explicit } C D \text { recipient } \\
\text { consent }\end{array}$ & $\begin{array}{l}\text { Made available with explicit } \\
\text { CD recipient consent }\end{array}$ & $\begin{array}{l}\text { Made available with explicit } \\
C D \text { recipient consent }\end{array}$ & $\begin{array}{l}\text { Made available with } \\
\text { explicit } C D \text { recipient } \\
\text { consent }\end{array}$ \\
\hline \multicolumn{5}{|l|}{ Final CD output } \\
\hline $\begin{array}{l}\text { High-level summaries } \\
\text { of strategic final CD } \\
\text { output } \\
\text { ( }(26-27) \\
\text { Non-public } \\
\end{array}$ & $\begin{array}{l}\text { Made available with } C D \\
\text { recipient consent based } \\
\text { on a } 20 \text {-business day } \\
\text { lapse-of-time }\end{array}$ & $\begin{array}{l}\text { Made available with CD } \\
\text { recipient consent based on } \\
\text { a } 20 \text {-business day lapse-of- } \\
\text { time }\end{array}$ & $\begin{array}{l}\text { Made available with CD } \\
\text { recipient consent based on } \\
\text { a } 20 \text {-business day lapse-of- } \\
\text { time }\end{array}$ & $\begin{array}{l}\text { Made available with CD } \\
\text { recipient consent based } \\
\text { on a } 20 \text {-business day } \\
\text { lapse-of-time }\end{array}$ \\
\hline $\begin{array}{l}\text { Other final CD output } \\
\text { (e.g., full TA reports, } \\
\text { CD recipient-specific } \\
\text { final training materials } \\
\text { final aide-mémoires, } \\
\text { draft legislation } \\
\text { provided by TA } \\
\text { missions) ( }(23,24,26) \\
\text { Non-public }\end{array}$ & $\begin{array}{l}\text { Made available with CD } \\
\text { recipient consent based } \\
\text { on a } 20 \text {-business day } \\
\text { lapse-of-time }\end{array}$ & $\begin{array}{l}\text { Made available with } C D \\
\text { recipient consent based on } \\
\text { a } 20 \text {-business day lapse-of- } \\
\text { time }\end{array}$ & $\begin{array}{l}\text { Made available with CD } \\
\text { recipient consent based on } \\
\text { a } 20 \text {-business day lapse-of- } \\
\text { time }\end{array}$ & $\begin{array}{l}\text { Made available with } \\
\text { explicit } C D \text { recipient } \\
\text { consent }\end{array}$ \\
\hline $\begin{array}{l}\text { Non-CD recipient specific } \\
\text { information } \\
\text { (e.g., non-CD recipient } \\
\text { specific training, Policy } \\
\text { Issue Notes, etc.) ( }(35) \\
\text { May be made public }\end{array}$ & Available & Available & Available & Available \\
\hline
\end{tabular}

